\title{
The visual reaction time distribution in the tasks with different demands on information processing
}

\author{
Rudolf Psotta* \\ Faculty of Physical Culture, Palacký University, Olomouc, Czech Republic
}

Copyright: (C) 2014 R. Psotta. This is an open access article licensed under the Creative Commons Attribution License (http://creativecommons.org/licenses/by/4.0/).

\begin{abstract}
Background: Reaction tests are a part of the neuropsychological assessment of the individual. The design of these tests and selection of the appropriate measures of reaction time (RT) should come out from the distribution qualities of RTs. According to the newer general theory of RT distribution, the quality of RTs also depends on the specific properties of a reaction task. Objective: The aim of the study was to examine the dependency of RT distribution on an amount of processed information in a visual reaction test, and to verify the stability of RT distribution between two series of RTs in male adolescents. Methods: 25 male adolescents, aged $17.1 \pm 1.1$ years, performed four different eye-hand visual reaction tests which differed in a number of choices - simple reaction test $\left(\mathrm{RT}_{1}\right)$, two, three and fourchoice $\mathrm{RT}$ tests $\left(\mathrm{RT}_{2}, \mathrm{RT}_{3}, \mathrm{RT}_{4}\right)$. Each test involved 2 series with 20 reaction trials in each series, using the computerbased reactometer device. The first, second and third moments of the RT distribution were assessed - the measures of central tendency (mean, median), variability (\% $C V$, median absolute deviation/median ratio - MAD/Mdn, interquartile range) and normality (Kolmogorov-Smirnov test, skewness and kurtosis coefficient $\alpha$ and $\beta$ ). Significance of differences of RTs was assessed by the Wilcoxon test $(\alpha=.05)$. Results: The analysis showed the non-Gaussian distributions of RTs $(\alpha=.01)$ with the skew to the right $(\alpha=1.18-4.38)$ and leptocurtic distribution $(\beta=1.89-34.15)$ in all types of the RT tests. The measures of RT variability \% $C V$ and $M A D / M d n(\%)$ were lower for the $\mathrm{RT}_{1}$ test as compared to the $\mathrm{RT}_{2}, \mathrm{RT}_{3}$ and $\mathrm{RT}_{4}$ tests. No significant differences in $\mathrm{RTs}$ measured in the $1^{\text {st }}$ and $2^{\text {nd }}$ series of trials were found in the RT 1 test and $\mathrm{RT}_{2}$ test in contrast to significantly shorter RTs in the $2^{\text {nd }}$ series of trials in the $\mathrm{RT}_{3}$ test and $\mathrm{RT}_{4}$ test $(p=.006$ and $p<.001)$. RTs measured in the $2^{\text {nd }}$ series of trials of $\mathrm{RT}_{1}, \mathrm{RT}_{2}$ and $\mathrm{RT}_{4}$ tests manifested distribution with a higher skewness to the right and higher peakedness than the RTs in the $1^{\text {st }}$ series. Conclusions: The study supported the hypothesis on asymmetric distribution of RTs, specifically when measured in the both eye-hand visual simple and multiple-choice reaction tasks with two up to four choices. Thus, the nonparametric statistics show to be more appropriate for analysis of RTs than the parametric statistics. For both clinical and research purposes, the two series of twenty reaction trials in a computer-based test can provide a sufficient number of the RT data for reliable assessment of visual simple and choice-reaction abilities in the male adolescents.
\end{abstract}

Keywords: choice reaction, simple reaction, RT distribution, skewness, data stability, adolescent

\section{Introduction}

The visual simple and multiple-choice reaction tests are a part of the neuropsychological assessment of individuals in the various domains as evaluation of preconditions for professions in military, security and traffic services, further in sport, and diagnostics in medicine, physiotherapy and developmental psychology.

\footnotetext{
* Address for correspondence: Rudolf Psotta, Department of Natural Sciences in Kinanthropology, Faculty of Physical Culture, Palacký University, tř. Míru 115, 77111 Olomouc, Czech Republic. E-mail: rudolf.psotta@upol.cz
}

Reaction time (RT) measured in a simple reaction test reflects the time interval needed to detect the stimulus, select and program a movement response, and conduct of the neural commands from the central neural system to muscles. In comparison to a simple reaction time (SRT), the choice reaction time (CRT) includes the more complex cognitive information processing including distinguishing the exposed stimulus from other alternative stimuli and selection of appropriate response (Schmidt \& Lee, 2011).

With an increase in the number of choices in a reaction task the amount of information needed to be processed increases. This relation has been described by 
the Hick-Hyman law with definition of RT as a logarithmic function of the number of choices (Seow, 2005). SRTs and CRTs are usually used as the indicators of information processing capacities and psycho-motor executive functions in individuals (Moskowitz, 2003).

One of the issues of the visual RT tests is the setting of their appropriate length, e.g. the number of reaction trials needed for valid and reliable prediction of individual's psychomotor functioning. There is the psychometric rule that too short or too long a test may reduce the test validity (Blahuš, 1989). Because of the considerable sensitivity of RT to a range of psychological and physiological factors (e.g. Cote et al., 2009; Davranche, Audiffren, \& Denjean, 2006) rather long test procedures with hundreds of the reaction trials have been used in research on RTs (e.g. Sanders, 1998; Saville et al., 2011).

However, in both research and clinical practice the shortened test procedures with 20-60 reaction trials are used, exposed in one to three series of trials with short rest intervals between the series (e.g. Chmura, Krysztofiak, Ziemba, Nazar, \& Kaciuba-Uścilko, 1998; Czech Ministry of Transport, 2010; Dykiert, Der, Starr, \& Deary, 2012a; Zemková, Miklovič, \& Hamar, 2009a, 2009b). Then, several methodological problems may be connected to assessment of reaction abilities from a small number of RTs (Whelan, 2008). The first question is how many RTs or series (sets) of RTs are sufficient to obtain valid and reliable information. In some studies the mean of a certain count of the best RTs in the better or best of two or three series, respectively, of reaction trials was used to assess reaction ability of an individual (e.g. Zemková \& Hamar, 2009; Zemková et al., 2009a). This problem relates to the stability over repeated trials of RTs. Although using random ordering of stimuli and variable time intervals of their exposure, it is necessary to consider the possible influence of familiarization, learning effect and also the sequential effects of the immediately preceding stimulus and earlier stimuli on the response to a current stimulus (Gao, Wong-Lin, Holmes, Simen, \& Cohen, 2009).

Another problem is which outlying RTs to eliminate as potentially false, and so what method to use for their elimination from the data for calculation of outcome measures in a individual. Neurophysiological limits of visual perception and response selection form a clearer criterion for eliminating extremely short RTs, which could be caused by fast guessing (Hervey et al., 2006). According to Luce (1986) genuine RTs are at least $100 \mathrm{~ms}$.

The choice of a method for eliminating extremely long RT as the outliers is markedly more difficult. One of the possible approaches is to use an absolute time, percentage of the data or a proportion of standard deviations above mean as cutoffs (Whelan, 2008; Ratcliff, 1993). The disadvantage of using absolute cutoffs is that there is no reliable rule for setting such cut-offs due to high dependence on the particular observed data. Therefore, a proportion of SD above the mean seems to be more advantageous. However, the slow RTs located far from the RT mean or median demonstrate strong relationships with a number of cognitive and neurological conditions and thus diagnostic validity rather than the mean or best RTs (Saville et al., 2011).

The problem mentioned above is connected with a problem of the RT distribution. Although the parametric statistics is traditionally used for assessment of the central tendency and variability of RTs, the current studies on RT clearly have demonstrated the asymmetric (non-Gaussian) RT distribution characterized by a skew to the right, e.g. rise rapidly on the left to short RTs and having a long tail on the right to longer RTs (e.g. Whelan, 2008; Hervey et al., 2006). According to the newer general theory of RT distributions by Moscoso del Prado Martín (2008), the shape of RT distribution depends, besides the participants, on concrete properties of a reaction task. However, the potencial effect of the amount of information processing, e.g. a number of alternative couples of stimulus-response (R-S) involved in a visual reaction task has not been systematically investigated.

Therefore on the basis of the methodogical problems with the reaction tests highlighted above, the aim of the study was to examine the dependency of RT distribution on a number of choices (R-S) in an eye-hand visual reaction time test, and to verify the stability of reaction times and RT distribution between two series of RTs in male adolescents.

\section{Methods}

\section{Participants}

Twenty five male students of two high schools, aged $17.1 \pm 1.1$ years, variation range $15.6-20.7$ years participated in the study. All participants were physically active, and of normal intellect. The exclusion criteria for selection into the group of participants were attention disorder including ADHD, other neurological diseases, visual impairment and also sport expertise on the national level. These criteria were checked from a report of the school psychologist and physical education teacher, and from the verbal questioning with each participant. Immediately before testing, each participant was asked about their current health and mental condition. The individuals with the current physical and/or mental impairment were not tested. 
This study has been realized in a frame of the project which was approved by the faculty ethics committee before submitting to the Czech Science Foundation followed by the approval by the psychology and education panel of the Czech Science Foundation. The testing was carried out after receiving informed written consent from school principals, the participants and their parents unless the sons were 18.0 years of age.

\section{Data procedures}

In the four visual reaction tests with the different number of choices (S-R) - the simple reaction test $\left(\mathrm{RT}_{1}\right)$ and two, three and four-choice reaction tests $\left(\mathrm{RT}_{2}\right.$, $\mathrm{RT}_{3}$ and $\mathrm{RT}_{4}$, respectively), the RT distribution was assessed by the three moments of distribution (Saville et al., 2011) - by the central tendency measures of RTs as the first moments, variability measures of RTs as the second moments, and skewness and kurtosis as the third moments of RT distribution. The selected measures of these moments of RT distribution were also analysed on their stability between two series of reaction trials.

\section{The visual reaction time tests}

The visual RT tests were carried out using the computer-based reactometer device FiTRO Reaction Check (Fitronic s. r. o., Bratislava, Slovakia). The device was composed of buttons $(75 \times 75 \mathrm{~mm})$ connected through an interface to a computer with the software (more technical details on the device - see Zemková \& Hamar, 2009).

During one testing session each participant performed the $\mathrm{RT}_{1}, \mathrm{RT}_{2}, \mathrm{RT}_{3}$ and $\mathrm{RT}_{4}$ tests in a random order with a $5 \mathrm{~min}$ rest interval between individual tests. Each test included two series of twenty reaction trials on exposed visual stimuli, with 1 min rest interval between these two series of reaction trials. The task for the participant was to react as fast as possible with a correct response to each visual stimulus that appeared on the $380 \times 210 \mathrm{~mm}$ screenof, by pressing the appropriate button.

The geometric figures of a red colour on a white background were exposed as stimuli - a circle in the $\mathrm{RT}_{1}$ test, a circle and cross in the $\mathrm{RT}_{2}$ test; circle, square and cross in the $\mathrm{RT}_{3}$ test; and circle, square, triangle and cross in the $\mathrm{RT}_{4}$ test. The figures were generated by software in a random order with same probability, in random variable intervals of $100-3000 \mathrm{~ms}$ after pressing the button on the preceding stimulus. An incorrect response was not accepted. The RT was measured to the time of pressing the relevant button for the given stimulus.

In the case of the $\mathrm{RT}_{1}$ test, the participant controlled the button with the index finger of his preferred (writing) hand. For the choice reaction tests the buttons were placed on the table in a row at a distance of $20 \mathrm{~cm}$ from inner sides of two adjacent buttons. In the $\mathrm{RT}_{2}$ and $\mathrm{RT}_{4}$ tests one, and two buttons, respectively, were controlled with the right and left index fingers, and with right and left index and middle fingers, respectively. In the $\mathrm{RT}_{3}$ test two buttons were controlled with the index and middle finger of the preferred hand, and the rest third button with the index finger of the nonpreferred hand. Before each RT test, the participant was provided with verbal task instruction and performed ten practice trials.

\section{Statistical analysis}

The statistical analysis was carried out with the following sequential steps:

$1^{\text {st }}$ step: elimination of outlying short $\mathrm{RT} \leq 100 \mathrm{~ms}$.

$2^{\text {nd }}$ step: calculation of the parametric and non-parametric measures of the $1^{\text {st }}$ moment of RT distribution, e.g. central tendency - mean $(M)$ and median $(M d n)$ of RTs; the measures of the $2^{\text {nd }}$ moment of the RT distribution, e.g. variability - standard deviation $(S D)$ and coefficient of variation \% $C V(S D / M \cdot 100)$ as the parametric measures, and the median absolute deviation $(M A D)$, ratio $M A D / M d n$ and interquartile range $(I Q R)$ as the non-parametric measures.

These measures were calculated from all RTs of all participants, achieved in a given series of reaction trials of a given RT test, e.g. from 500 individual RTs (25 participants $\times 20 \mathrm{RTs})$. The intra-individual means, medians and \% $\mathrm{CV}$ of RTs were also calculated from 20 RTs achieved by a participant in a given series of RTs in the given RT test.

$3^{r d}$ step: testing of normality of the RT distribution for each series of reaction trials of a given RT test using the Kolmogorov-Smirnov test $(\alpha=.01$ ) (RTs from the entire group, $n=500$ ).

$4^{\text {th }}$ step: because the non-normal distribution of RTs in both $1^{\text {st }}$ and $2^{\text {nd }}$ series of reaction trials in the all RT tests was found in the $3^{\text {rd }}$ step, the following detailed measures of non-normality were calculated:

a) skewness as the deviation of the distribution from symmetry by calculation of the skewness coefficient $\alpha$, with the following interpretation: $\alpha=0$ implies the symmetry; $\alpha<0$ and $\alpha>0$ indicates the skew of the distribution to the left and right, respectively.

b) kurtosis of the distribution by calculation of the coefficient $\beta$, with the interpretation: $\beta>0$ implies a sharper peak of distribution around the mean with longer tails (leptokurtic distribution) in comparison with the normal distribution; $\beta<0$ indicates the distribution having a more rounded peak near the mean with shorter thinner tails (platykurtic distribution). 
Testing of normality of intra-individual RTs and calculation of skewness and kurtosis as $3^{\text {rd }}$ moment of RT distribution were not carried out due to their irrelevance in the case of calculation them from a small number of RTs $(n=20)$ in one series of reactions trials.

$5^{\text {th }}$ step: testing of difference between RTs achieved in the $1^{\text {st }}$ and $2^{\text {nd }}$ series of reaction trials in a given type of the RT test using the Wilcoxon matched-pairs test $(\alpha=.05)$. The RTs from the entire group were included.

For statistical analysis statistical software Statistica (Version 10; StatSoft, Inc., Tulsa, OK, USA) was used.

\section{Results}

Both mean and median of all RTs of all the group found in both $1^{\text {st }}$ and $2^{\text {nd }}$ series of reaction trials increased with an increasing a number of choices in the RT tests, e.g. from the $\mathrm{RT}_{1}$ test up to the $\mathrm{RT}_{4}$ test (Table 1). From the 600 intra-individual comparisons of the RT means and RT medians among all couples of the different types of the RT tests (while the series of trials of the same order compared), only seven and six comparisons, respectively, showed lower values in the RT test with a higher number of choices as compared to the RT test with lower number of choices.

As the measures of relative variability of RTs, both the parametric $C V(\%)$ and nonparametric $M A D / M d n$ ratio (\%) of the RTs of all the group were shown to be lower for the $\mathrm{RT}_{1}$ test than in the all multiple-choice reaction tests (Table 1). The intraindividual \% $\mathrm{CV}$ of RTs in the RT test were slightly lower than in the multiple-choice reaction tests - the mean of \% $\mathrm{CV}$ of RTs was in the $1^{\text {st }}$ and $2^{\text {nd }}$ series of reaction trials $18.8 \%$ and $21.4 \%$ in the $\mathrm{RT}_{1}$ test in comparison with $23.4 \%$ and $19.1 \%$ in the $\mathrm{RT}_{2}$ test, $22.4 \%$ and $24.4 \%$ in the in the $\mathrm{RT}_{3}$ test, and $21.2 \%$ and $22.6 \%$ in the $\mathrm{RT}_{4}$ test.

In each type of the RT test and series of the reaction trials, the median of the RTs of all the group was lower than the mean of these RTs (Table 1). This finding suggested the non-normal RT distributions subsequently confirmed by the results of the Kolmogorov-Smirnov test (Figures 1-4). In addition, the medians of intraindividual RTs were shorter than intra-individual RT means in the $76 \%, 80 \%, 86 \%$ and $82 \%$ of the individual series of 20 reaction trials in the $\mathrm{RT}_{1}, \mathrm{RT}_{2}, \mathrm{RT}_{3}$ and $\mathrm{RT}_{4}$ test, respectively. These results suggested a high prevalence of asymmetrical distribution of the intraindividual RTs.

Positive values of the skewness coefficient $\alpha$ found for the distribution of RTs of all the group in all the types of RT tests indicated a clear skew of the RT distribution to the right, e.g. to longer RTs (Figures 1-4). Concurrently with this skewness, the RT distribution in all the RT tests was shown to be more peaked than the normal one is as the kurtosis coefficients $\beta$ were positive (Figures 1-4).

Results of the Wilcoxon test showed no significant difference in RTs of all the group achieved in the $1^{\text {st }}$ series and $2^{\text {nd }}$ series of reaction trials, both in the $\mathrm{RT}_{1}$ test and $\mathrm{RT}_{2}$ test $(z=0.423, p=.672$, and $z=1.412$, $p=.157)$. On the other hand, RTs of all the group

Table 1

The parametric and nonparametric measures of reaction times (RTS) of all the group achieved in the $I^{\text {st }}$ and $2^{\text {nd }}$ series of twenty reaction trials (calculated from $500 R T s ; 25$ subjects $\times 20$ trials) in the $R T_{p}$, $R T_{2}, R T_{3}$ and $R T_{4}$ test

\begin{tabular}{lcccccccc}
\hline & \multicolumn{3}{c}{ Parametric measures } & & \multicolumn{5}{c}{ Nonparametric measures } \\
\cline { 2 - 3 } \cline { 8 - 9 } Test/set & $M(\mathrm{~ms})$ & $S D(\mathrm{~ms})$ & $C V(\%)$ & & $M d n(\mathrm{~ms})$ & $M A D(\mathrm{~ms})$ & $M A D / M d n(\%)$ & $\operatorname{IQR}(\mathrm{ms})$ \\
\hline $\mathrm{RT}_{1-1}$ & 356 & 80 & 22.5 & & 346 & 41 & 11.8 & 82 \\
$\mathrm{RT}_{1-2}$ & 358 & 87 & 24.3 & & 343 & 44 & 12.8 & 89 \\
$\mathrm{RT}_{2-1}$ & 553 & 159 & 28.8 & & 527 & 86 & 16.3 & 175 \\
$\mathrm{RT}_{2-2}$ & 536 & 133 & 24.8 & & 516 & 71 & 13.8 & 141 \\
$\mathrm{RT}_{3-1}$ & 645 & 203 & 31.5 & & 609 & 86 & 14.1 & 175 \\
$\mathrm{RT}_{3-2}$ & 623 & 187 & 30.0 & & 598 & 94 & 15.7 & 187 \\
$\mathrm{RT}_{4-1}$ & 712 & 185 & 36.0 & & 681 & 107 & 15.7 & 221 \\
$\mathrm{RT}_{4-2}$ & 680 & 177 & 26.0 & & 655 & 98 & 15.0 & 204 \\
\hline
\end{tabular}

Note. $\quad C V=$ coefficient of variation, $M d n=$ median, $M A D=$ median absolute deviation, $M A D / M d n=$ median absolute deviation/median ratio, $I Q R=$ interquartile range. $\mathrm{RT}_{1-1}, \mathrm{RT}_{1-2}=$ reaction times in $1^{\text {st }}$ and $2^{\text {nd }}$ series of reaction trials in the simple reaction test, $\mathrm{RT}_{2-1} ; \mathrm{RT}_{2-2}=$ reaction times in $1^{\mathrm{st}}$ and $2^{\text {nd }}$ series of reaction trials in the two-choice reaction test; $\mathrm{RT}_{3-1}, \mathrm{RT}_{3-2}=$ reaction times in $1^{\text {st }}$ and $2^{\text {nd }}$ series of reaction trials in the three-choice reaction test; $\mathrm{RT}_{4-1}, \mathrm{RT}_{4-2}=$ reaction times in $1^{\text {st }}$ and $2^{\text {nd }}$ series of trials in the four-choice reaction test. 

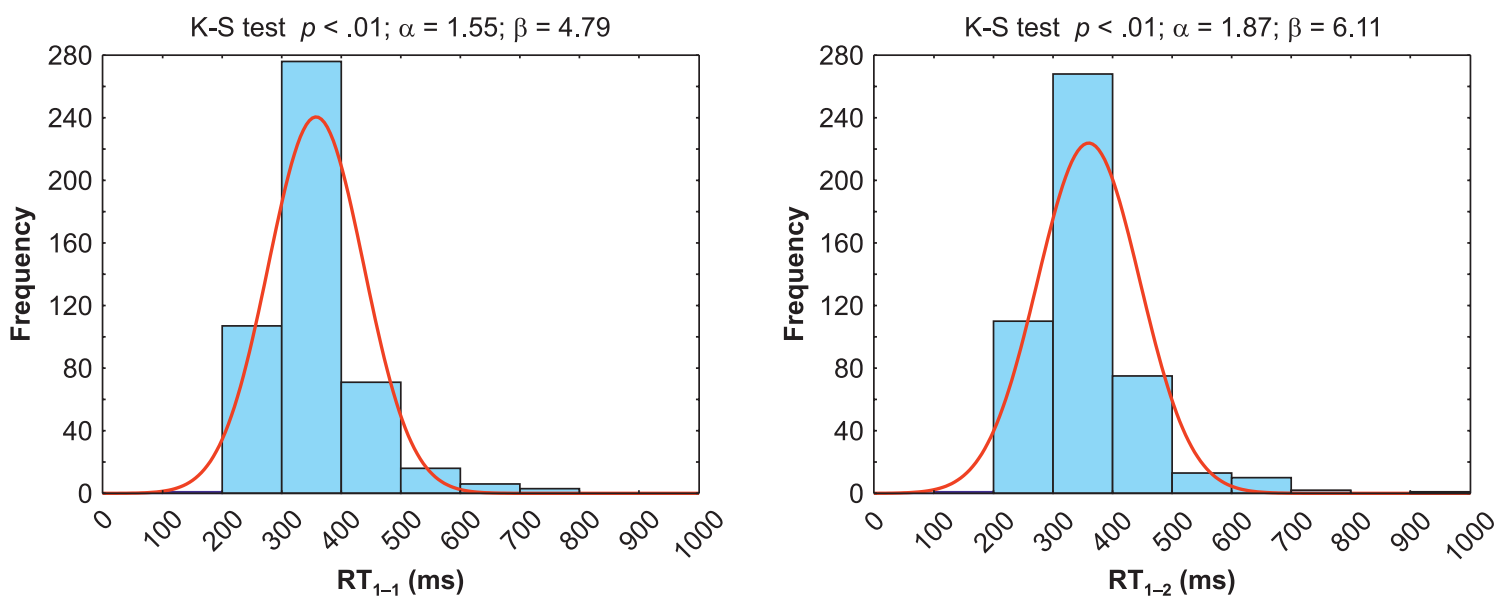

Figure 1. Reaction time distributions found in the simple reaction test. $\mathrm{RT}_{1-1}, \mathrm{RT}_{1-2}=$ reaction times in the $1^{\text {st }}$ and $2^{\text {nd }}$ series of reaction trials, respectively, of the simple reaction test. K-S test $=$ Kolmogorov-Smirnov test, $p=$ a level of significance, $\alpha=$ skewness coefficient, $\beta=$ kurtosis coefficient.
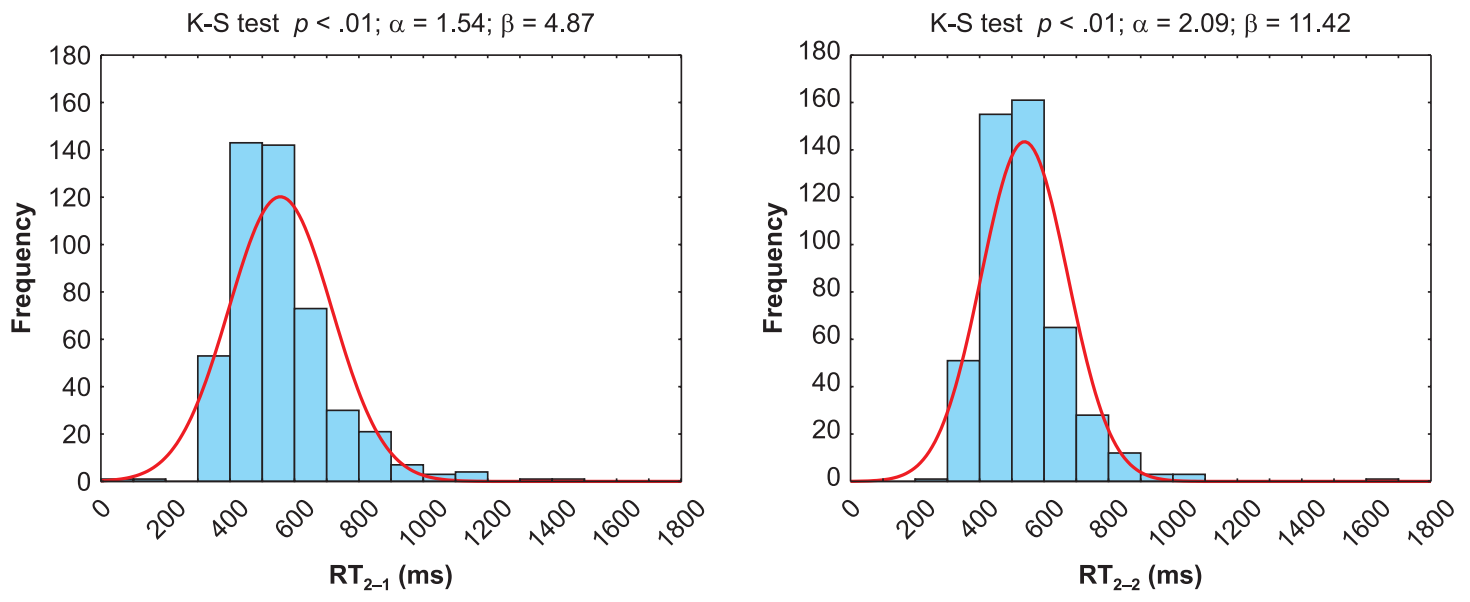

Figure 2. Reaction time distributions found in the two-choice reaction test. $\mathrm{RT}_{1-1}, \mathrm{RT}_{1-2}=$ reaction times in the $1^{\text {st }}$ and $2^{\text {nd }}$ series of reaction trials, respectively, of the simple reaction test. K-S test $=$ Kolmogorov-Smirnov test, $p=$ a level of significance, $\alpha=$ skewness coefficient, $\beta=$ kurtosis coefficient.
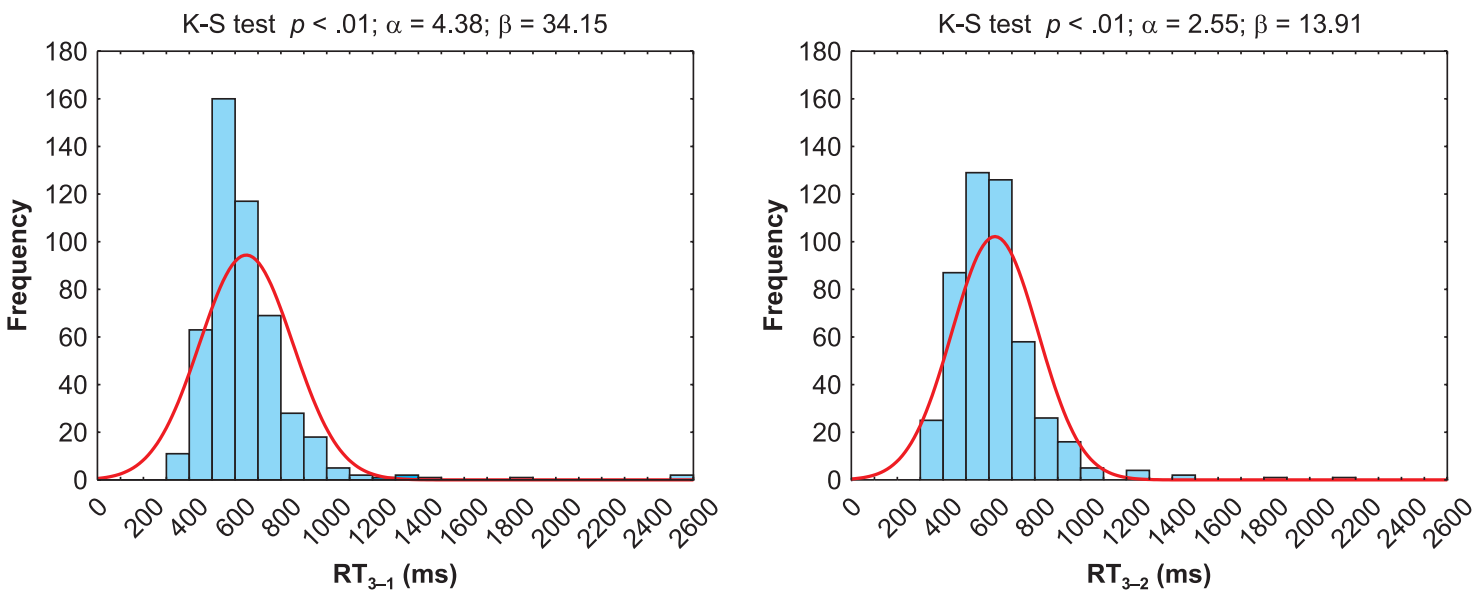

Figure 3. Reaction time distributions found in the three-choice reaction test. $\mathrm{RT}_{1-1}, \mathrm{RT}_{1-2}=$ reaction times in the $1^{\text {st }}$ and $2^{\text {nd }}$ series of reaction trials, respectively, of the simple reaction test. K-S test $=$ Kolmogorov-Smirnov test, $p=$ a level of significance, $\alpha=$ skewness coefficient, $\beta=$ kurtosis coefficient. 

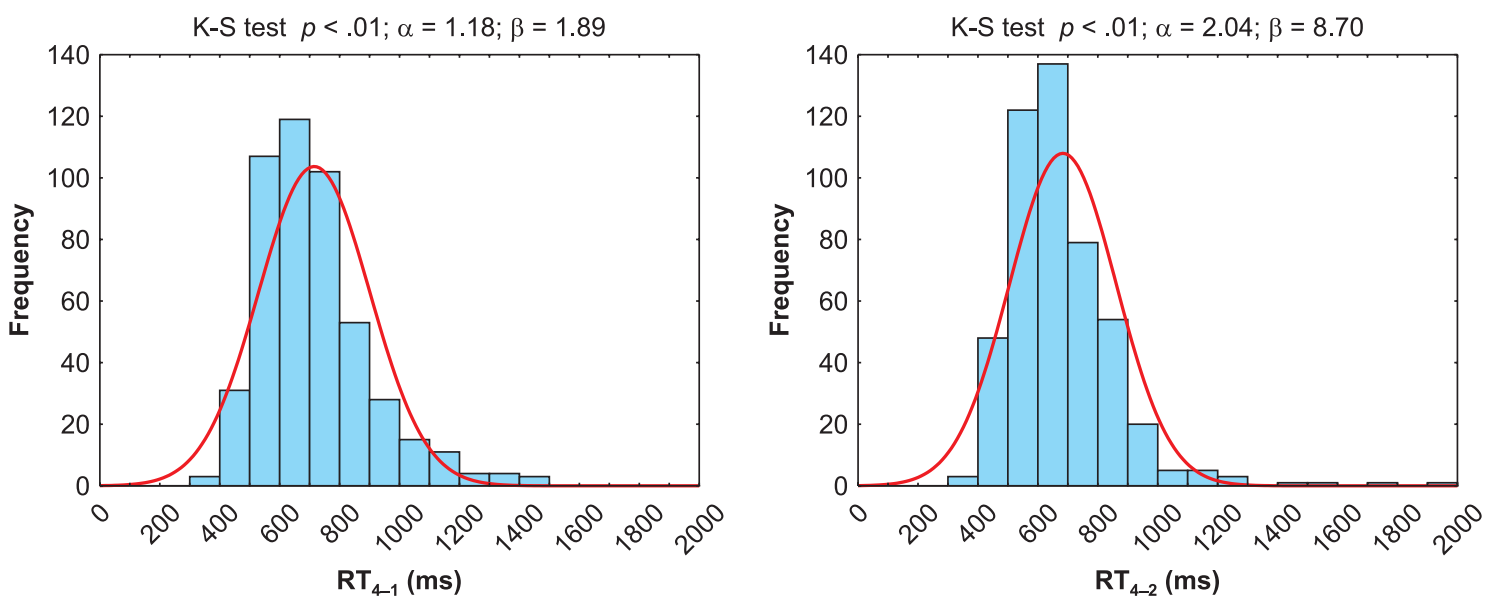

Figure 4. Reaction time distributions found in the four-choice reaction test. $\mathrm{RT}_{1-1}, \mathrm{RT}_{1-2}=$ reaction times in the $1^{\text {st }}$ and $2^{\text {nd }}$ series of reaction trials, respectively, of the simple reaction test. K-S test $=$ Kolmogorov-Smirnov test, $p=$ a level of significance, $\alpha=$ skewness coefficient, $\beta=$ kurtosis coefficient.

achieved in the $2^{\text {nd }}$ series of reaction trials of both the $\mathrm{RT}_{3}$ test and $\mathrm{RT}_{4}$ test were significantly shorter than those in the $1^{\text {st }}$ series $(z=2.756, p=.006$, and $z=3.552, p<.001)$. However, if the intra-individual comparisons of RTs were performed, only three and four participants achieved significantly shorter RTs in the $2^{\text {nd }}$ series of reaction trials than in the first one in the $\mathrm{RT}_{3}$ test and $\mathrm{RT}_{4}$ test, respectively.

When the coefficients $\alpha$ and $\beta$ for RTs of all the group measured in the $1^{\text {st }}$ and $2^{\text {nd }}$ series of reaction trials were compared, the RT distribution measured in the $2^{\text {nd }}$ series of trials showed to be more skewed to the right and concurrently more peaked in comparison with the RTs in $1^{\text {st }}$ trials, in the all types of RT tests with exception of the $\mathrm{RT}_{3}$ test (Figures 1-4).

If the $\mathrm{M}+3 \mathrm{SD}$ value was used as the cutoffs criterion, the elimination of long outlying RTs would affect $0.8 \%, 1.1 \%, 1.4 \%$ and $1.4 \%$ of RTs in the $\mathrm{RT}_{1}, \mathrm{RT}_{2}, \mathrm{RT}_{3}$ and $\mathrm{RT}_{4}$ test, respectively.

\section{Discussion}

The aim of the study was to examine the distribution of visual RTs including central tendency, variability and normality of RTs, with the focus on the dependency of these distribution qualities of RTs on the amount of processed information, e.g. a number of the choices involved in a reaction task. The mean of RTs of all the group achieved in the $1^{\text {st }}$ and $2^{\text {nd }}$ series of the reaction trials prolonged with the increase in a number of choices - by $55.3 \%$ and $49.7 \%$, respectively, in the RT test as compared to the RT test, by $16.6 \%$ and $16.2 \%$, respectively, in $\mathrm{RT}_{3}$ test as compared to the $\mathrm{RT}_{2}$ test, and by $10.4 \%$ and $8.4 \%$, respectively, in the $\mathrm{RT}_{4}$ test as compared to the $\mathrm{RT}_{3}$ test.

The same trend of prolongation of RTs with an increase in a number of choices was observed if the median of RTs of all the group was used. This trend was confirmed in other studies focused on the visual reaction; specifically the shorter RTs in the simple reaction task as compared with the RTs in the two-choice reaction task in the football players (Straume-Naesheim, Andersen, \& Bahr, 2005) and four-choice reaction task in the children and adolescents (Der \& Deary, 2006; Dykiert et al., 2012a).

Even though the aim of the study was not to verify the fit of the RTs to the logarithmic function according to the Hick-Hyman law (Seow, 2005), the progressive reduction in increment of the RT with increasing number of choices (see the data above in the $1^{\text {st }}$ paragraph of the discussion) suggested the relevance to the logarithmic model of RTs and so the validity of the RTs obtained in this study. This conclusion was also supported by the results of the intra-individual comparisons of both the mean RT and median RT achieved in any couple of the RT tests with the different number of choices. $94.3 \%$ and $94.7 \%$ of these intra-individual comparisons corresponded to the following theoretical suggestion: $\mathrm{RT}_{1}<\mathrm{RT}_{2}<\mathrm{RT}_{3}<\mathrm{RT}_{4}$.

An interesting trend observed was the lower variability of RTs of all the group indicated by \% $\mathrm{CV}$ and the $M A D / M d n$ ratio in the simple reaction $\left(\mathrm{RT}_{1}\right)$ test than in the multiple-choice reaction tests. As calculated from the RTs from all participants, these measures reflect both inter- and intra-individual variability of RTs. However, the findings of slightly lower \% $\mathrm{CV}$ of the intra-individual RTs in the $\mathrm{RT}_{1}$ test than in the 
multiple-choice tests (see $2^{\text {nd }}$ paragraph of the results) could support the suggestion about the tendency of the lower intra-individual variability of RTs in the visual simple reaction task as compared with the multiplechoice reaction tasks. In the study by Dykiert et al. (2012a) it is possible clearly deduce the lower intraindividual variability of RTs in the simple reaction task in the participants under 18 years. This deducation is based on the fact that the mean intra-individual standard deviation of RTs was found more than seven times lower in the simple reaction task than in the four-choice reaction task while intra-individual mean of RTs in the simple reaction task was roughly two times lower only. One can hypothesized that with more complex cognitive information processing and decision about motor response the more extensive fluctuation of RTs could be expected.

Also the inter-individual variability of RTs seemed to be lower in the simple reaction test than in the multiple-choice reaction tests. This suggestion was deduced from the fact that differences between the inter-individual \% $C V$ of RTs (Table 1) and the mean intra-individual \% $C V$ of RTs (see results) were larger for the multiple-choice reaction tests as compared with the slight difference between these two types of \% $\mathrm{CV}$ of RTs in the simple reaction test. Because multiple-choice reactions are associated with higher demands on cognitive information processing, the individual differences in perceptual and cognitive functioning could reflect into the larger inter-individual differences in RTs. It has been considered the inter-individual variability in a wide range of basic and higher cognitive functions including perception, motor control, memory, attention and metacognition (Kanai \& Rees, 2011).

The Kolmogorov-Smirnov test applied on RTs of all the group indicated the non-normal RT distributions, both in the $\mathrm{RT}_{1}$ test and multiple-choice reaction tests. According to the skewness coefficients $\alpha$ (Figures 1-4) the cause of the RT non-normality was a skew to the right towards longer RTs. Although the distribution normality of intra-individual RTs was not analysed for a small number of individual RTs in one series $(n=20), 80 \%$ of the individual series of the trials had the shorter median RT in comparison to the mean RT. The findings of the kurtosis coefficient $\beta>0$ (Figures 1-4) presented the leptocurtic RT distributions and indicated a larger number of RTs around the RT mean. The shapes of the non-normal RT distribution revealed for both visual simple and choice reaction tests in the study correspond to the respected model of the nonGaussian RT distribution (Palmer \& Horowitz, 2011; Whelan, 2008).

The study was also focused on examination of RT stability between two exposed series of RTs separated with one-minute rest interval in each type of the RT test used. When RTs from all the group were included, no significant difference between RTs performed in the $1^{\text {st }}$ and $2^{\text {nd }}$ series of reaction trials were found in the $\mathrm{RT}_{1}$ test and $\mathrm{RT}_{2}$ test $(\alpha=.05)$. In addition, while doing the intra-individual comparisons, only one from 25 participants achieved significantly shorter RTs in the $2^{\text {nd }}$ series of trials than in the $1^{\text {st }}$ series of trials in the $\mathrm{RT}_{2}$ test, and even one participant significantly shorter RTs already in the $1^{\text {st }}$ series of trials than in the $2^{\text {nd }}$ series of trials of the $\mathrm{RT}_{1}$ test $(\alpha=.05)$.

In contrast to the $\mathrm{RT}_{1}$ and $\mathrm{RT}_{2}$ tests, in the $\mathrm{RT}_{3}$ and $\mathrm{RT}_{4}$ tests RTs in the $2^{\text {nd }}$ series of trials were significantly shorter than RTs in $1^{\text {st }}$ series $(\alpha=.05)$ when RTs of all the group were included into the analysis. When intraintraindividual comparisons of RTs were completed ( $\alpha=.05$ ), 11 and 15 of 25 participants demonstrated for the $\mathrm{RT}_{3}$ test and the $\mathrm{RT}_{4}$ test, respectively, a shorter median of RTs in the $2^{\text {nd }}$ series of trials as compared to the RTs in the $1^{\text {st }}$ series of trials. However, these differences were significant only in the three and four participants, respectively. In spite of the suggestion about the improvement in RTs during three or four series of reaction trials due to familiarization and/or learning effect (Zemková \& Hamar, 2009), these results indicate that if the particular stimuli are exposed in a random order and in randomly variable time intervals, and a preceding short practice (ten trials in the study), RT in the $2^{\text {nd }}$ repeated series of reaction trials may not differ significantly from RT from the $1^{\text {st }}$ series, especially in the $\mathrm{RT}_{1}$ and $\mathrm{RT}_{2}$ tests.

The RT stability between two series of reaction trials was also evaluated by the stability of the third moment of RT distribution - the skewness. A slight increase in skewness of RT distribution to the right was observed in the $2^{\text {nd }}$ series of RTs in all RT tests with exception of the $\mathrm{RT}_{3}$ test. While the non-significant differences of RT in $1^{\text {st }}$ and $2^{\text {nd }}$ series of trials mentioned above, the increased skewness to the right could indicate some reduction in the proportion of outlying long RT with concurrent increasing of their "outlyingness" from the mean.

Despite the study by Saville et al. (2011) suggesting twenty reaction trials not to be sufficient number of trials for acceptable reliability of the intra-individual RT variability measures, this study has suggested quite good stability of RTs for the first series of twenty trials, however, rather for the simple and two-choice reaction tests than for the tests with higher number of choices.

The validity of the results of this study could be partly limited by standard error of measurement of RTs $7.1 \%$ reported for the reactometer device used (Zemková \& Hamar, 2009). However, this reliability is similar or better as compared with reliability of other 
computerized RT tests involved in the neuropsychological test batteries as the ImPact with 1 week testretest reliability $I C C=.78-.88$ in young adults subjects (Resch et al., 2013), the ANAM battery with 1 week test-rest reliability $r=.29-.46$, and $I C C=.24-.38$ in the adolescents (Segalowitz et al., 2007), and the Cogsport tests with 2 weeks test-retest reliability $I C C=.73$ for SRTs, and $I C C=.65$ for CRTs in football players (Straume-Naesheim, Andersen \& Bahr, 2005). The logical limitation of the study is that interpretation of the findings are valid for male adolescents only due to age and sex differences in RTs and their intra-individual variability (Dykiert et al., 2012a, 2012 b; Silverman, 2006).

\section{Conclusion}

The study showed the both simple and two, three and four-choice eye-hand visual reaction times measured in male adolescents have an asymmetric distribution with a skew to the right and concurrently higher peakedness in comparison to the normal Gaussian model. Therefore, in contrast to traditional use of parametric measures, nonparametric measures should be used for the both inter- and intra-individual analyses of reaction times. The study showed the two series of twenty reaction trials in a computer-based test provide a sufficient number of reaction times for reliable assessment of visual simple reaction and choice-reaction abilities in the male adolescents.

\section{Acknowledgment}

The study was supported by the Czech Science Foundation in the frame of the project No. P407/11/0946.

I thank the principals, teachers and students of two high schools in Prague and Olomouc for participation in the study. I would like to thank my students Michal Bělovský, Mgr. Ludvík Valtr and Bc. Svatoslav Valenta for assistance during data collecting, and prof. Jan Hendl for consultation about the statistics.

\section{References}

Blahuš, P. (1989). Základní pojmy statistické teorie psychologických testů [Basic concepts of the statistical theory of psychological testing]. Československá psychologie, 33, 223-241.

Chmura, J., Krysztofiak, H., Ziemba, A. W., Nazar, K., \& Kaciuba-Uścilko, H. (1998). Psychomotor performance during prolonged exercise above and below the blood lactate threshold. European Journal of Applied Physiology, 77, 77-80.

Cote, K. A., Milner, C. E., Smith, B. A., Aubin, A. J., Greason, T. A., Cuthbert, B. P., ... Duffus, S. E. G. (2009). CNS arousal and neurobehavioral performance in a short-term sleep restriction paradigm. Journal of Sleep Research, 18, 291-303.

Czech Ministry of Transport. (2010). Manuál doporučených psychodiagnostických metod pro vyšetřování a posuzování psychické způsobilosti $k$ řizení motorických vozidel [Manual of diagnostic psychological methods for screening and assessment of psychological competency to driving cars]. Praha: Author. Retrieved from http://www.contexo.cz/files/ other/filemanager/Files/Doprava/Manual_doporucene_ psdg_postupy.pdf/

Davranche, K., Audiffren, M., \& Denjean, A. (2006). A distributional analysis of the effect ofphysical exercise on a choice reaction time task. Journal of Sports Sciences, 24, 323-330.

Der, G., \& Deary, I. J. (2006). Age and sex differences in reaction time in adulthood: Results from the United Kingdom health and lifestyle survey. Psychology and Aging, 21, 62-73.

Dykiert, D., Der, G., Starr, J. M., \& Deary, I. J. (2012a). Sex differences in reaction time mean and intraindividual variability across the life span. Developmental Psychology, 48, 1262-1276.

Dykiert, D., Der, G., Starr, J. M., \& Deary, I. J. (2012b). Age differences in intra-individual variability in simple and choice reaction time: Systematic review and metaanalysis. PLOS ONE, 7(10), e45759. doi:10.1371/journal. pone.0045759.

Gao, J., Wong-Lin, K., Holmes, P., Simen, P., \& Cohen, J. (2009). Sequential effects in two-choice reaction time tasks: Decomposition and synthesis of mechanisms. Neural Computation, 21, 2407-2436.

Hervey, A. S., Epstein, J. N., Curry, J. F., Tonev, S., Arnold, L. E., Conners, C. K., ... Hechtman, L. (2006). Reaction time distribution analysis of neuropsychological performance in an ADHD sample. Child Neuropsychology, 12, 125-140.

Kanai, R., \& Rees, G. (2011). The structural basis of interindividual differences in human behaviour and cognition. Neuroscience, 12, 231-242.

Luce, R. D. (1986). Response times: Their role in inferring elementary mental organization. New York, NY: Oxford University Press.

Moscoso del Prado Martín, F. (2008). A theory of reaction time distributions. Retrieved from http://cogprints. org/6310/1/recinormal.pdf

Moskowitz, H. (2003). New directions - processing (response) time as an indicator of cognitive processes and its possible link with sensory attributes. Journal of Sensory Studies, 18, 144-162.

Palmer, E. M., \& Horowitz, T. S. (2011). What are the shapes of response time distributions in visual search? Journal of Experimental Psychology: Human Perception and Performance, 37, 58-71.

Ratcliff, R. (1993). Methods for dealing with reaction time outliers. Psychological Bulletin, 114, 510-532. 
Resch, J., Driscoll, A., McCaffrey, N., Brown, C., Ferrara, M. S., Macciocchi, S., ... Walpert, K. (2013). ImPact testretest reliability: Reliably unreliable? Journal of Athletic Training, 48, 506-511.

Sanders, A. F. (1998). Elements of human performance: Reaction processes and attention in human skill. Mahwah, NJ: Lawrence Erlbaum Associates Publishers.

Saville, C. W. N., Pawling, R., Trullinger, M., Daley, D., Intriligator, J., \& Klein, C. (2011). On the stability of instability: Optimising the reliability of intra-subject variability of reaction times. Personality and Individual Differences, 51, 148-153.

Schmidt, R. A., \& Lee, T. D. (2011). Motor control and learning (5th ed.). Champaign, IL: Human Kinetics.

Segalowitz, S. J., Mahaney, P., Santesso, D. L., MacGregor, L., Dywan, J., \& Willer, B. (2007). Retest reliability in adolescents of a computerized neuropsychological battery used to assess recovery from concussion. NeuroRehabilitation, 22, 243-251.
Seow, S. C. (2005). Information theoretic models of HCI: A comparison of the Hick-Hyman law and Fitt's law. HumanComputer Interaction, 20, 315-352.

Silverman, I. W. (2006). Sex differences im simple visual reaction time: A historical meta-analysis. Sex roles, 54, 57-68.

Straume-Naesheim, T. M., Andersen, T. E., \& Bahr, R. (2005). Reproducibility of computer based neuropsychological testing among Norwegian elite football players. British Journal of Sports Medicine, 39(Suppl. I), 64-69.

Whelan, R. (2008). Effective analysis of reaction time data. The Psychological Record, 58, 475-482.

Zemková, E., \& Hamar, D. (2009). Toward an understanding of agility performance. Boskovice: Albert.

Zemková, E., Miklovič, P., \& Hamar, D. (2009a). There is a relationship between intensity of exercise and reaction time on laterally concordant and discordant stimuli. Acta Kinesiologica, 3(1), 59-63.

Zemková, E., Miklovič, P., \& Hamar, D. (2009b). Visual reaction time and sway velocity while balancing on a wobble board. Kinesiologia Slovenica, 15(3), 40-47. 